\title{
Inventory Model for COVID-19 Medicine under Carbon Emissions Sensitive Demand
}

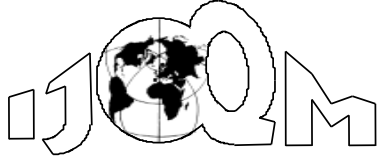

DOI: $10.46970 / 2021.27 .3 .3$

Volume 27, Number 3

September 2021, pp. 237-244
Nita H. Shah

Ekta Patel

Kavita Rabari

Gujarat University

(nitahshah@gmail.com)

(ektapatel1109@gmail.com)

(kavitagalchar1994@gmail.com)

In the second wave of COVID-19 pandemic, there is another challenge to face: how to effectively dispense some medicines (like Remdesivir injection) amongst the multitudes to quickly achieve immunity against the corona infection. To overcome this situation, researchers and doctors are continuously active. This result into infected people get recovered. In this context, nations are now getting ready to face one more big challenge that is increases biomedical waste which causes carbon emissions. Since spoilage and deterioration results into a significant loss in medicines which hampers consumer's satisfaction level as well affect the green environment. Keeping this in mind, the proposed article is addressed for an inventory model with carbon emissions sensitive demand which is a more realistic assumption and carbon tax policy is levied to diminish carbon emissions. A non-linear formulation is revealed with an objective to determine the optimum cycle length as to minimize total cost. The validity of the proposed model is demonstrated by presenting a numerical example. Sensitivity analysis is carried out to verify its factual practice.

Keywords: Medication Inventory, Carbon Emissions Dependent Demand, Carbon Tax, Spoilage of Injections

\section{Introduction}

Critical acute lung syndrome corona virus has created terrific fear around the world amid rapid transmission and high mortality. The outbreak of the corona virus emerged from Wuhan city, China in December 2019 and spread over more than 200 countries. Epidemiologists conclude that this pandemic may remain till an undefined period and more cases and deaths may occur. After that a little bit of relief from pharmaceutical companies by the launch of a generic version of Remdesivir and Favipiravir for covid19 treatment. But this relief is not permanent, with the huge use of this type of medicines, pose a threat to human body and also global changing if not scientifically handled and disposed. Nowadays, some countries are attentive to reduce carbon emissions because it is the key factor of global warming. To be part of this competitive green market, it is a necessity to provide the end procedure of the product i.e., from the manufacturing of the product to the end customer with less carbon output. Efficient management plays a vital role in saving the environment from hazardous carbon emissions as well as optimizing the total cost because medicines require refrigerating technologies, transportation and quality preservation tactics, etc. which results in 
increased carbon emission. Moreover, it is rarely noticed that the pharmacy sector evokes air pollution, smokestack, environmental damages, etc. The rest of the article is structured as follows: Literature survey is exhibited in section 2 . The assumptions and notations are presented in section 3 . The description of the problem is derived in section 4. Numerical validation is done in section 5 to test the model. Sensitivity analysis is carried out in section 6 . Finally, Section 7 concludes the proposed model.

\section{Literature Survey}

Now-a-days, the environment is badly affected by global warming as it increases sea levels, frequency of floods, storms, etc., and this situation is caused by carbon emissions. In business, Carbon emissions occur because of storing deteriorating products, shipping, and warehousing. The emissions from the warehousing inventory are subject to the whole inventory, along with the energy that has been used for the items in the warehouse. Disposable items are also a dominating factor. Hence, carbon emissions reduction has come to be a global challenge for researchers. So, keeping this in mind, Benjaafar et al. (2012) were the first to present how carbon emissions concern in operational decision making with respect to manufacturing, procurement, and inventory management. Then, Bouchery et al. (2012) developed a sustainable order quantity model by providing different regulatory policies to control carbon emissions. Chen et al. (2013) derived an EOQ model which shows the difference in the magnitude of emission reduction and cost increase by adopting environmental regulations like carbon caps, carbon tax, cap and offset. He et al. (2015) examined a production model in which optimal lot-size and emissions under a carbon tax and capand-trade are achieved also comparing these two regulations. Dye and Yang (2015) proposed an inventory model by considering sustainability in the perspective of joint trade credit and inventory decisions under different environmental policies. Furthermore, this model is extended with carbon offset. Datta (2017) established a production inventory model in which production rate is assumed to be a decision variable and concluding that emissions can be reduced by investing in green technology. Mishra et al. (2019) scrutinized a mathematical model by assuming price dependent demand and it is a function of setup cost and carbon emission. Power generation, transmission substations and distribution substations are taken into considerations for a sustainable electricity supply chain model. Mishra et al. (2020) investigated a sustainable economic production quantity model with carbon tax and cap in which three types of models are studied: (i) model with no shortages, (ii) with partial backordering and (iii) with full backordering with and without green technology investment. Mishra et al. (2021) established a sustainable inventory model with carbon cap and carbon tax policies taking into consideration linear and non-linear price dependent demand. This study explores carbon emissions can be reduced by investing in preservation and green technology. For the first time, Shah et al. (2021) analyzed carbon emissions in the COVID-19 vaccine and carbon tax policy is taken into consideration to achieve the environmental goals. Sarkar et al. (2021) proposed a three-echelon sustainable supply chain model in which to control carbon emissions reduce defective production and maintain the exact order as demand. Yadav and Khanna (2021) define an inventory model by considering price-sensitive demand and this study concludes carbon tax policy is a more realistic and operative tool to mitigate carbon emissions. 


\section{Assumption and Notations}

Notations which have been used to construct the proposed model are exhibited in this section.

\subsection{Notation}

Notations are given below in Table 1.

Table 1 Inventory Parameters

\begin{tabular}{|c|l|}
\hline \multicolumn{2}{|l|}{ Parameters } \\
\hline$A$ & Set-up cost (\$ /order). \\
\hline$h$ & Holding cost (\$ /Injection /unit of time). \\
\hline$c$ & Purchase cost (\$ /injection). \\
\hline$C_{T}$ & Carbon tax (\$). \\
\hline$k$ & Carbon emissions elasticity. \\
\hline$\theta$ & Deterioration rate for injection. \\
\hline \multicolumn{2}{|c|}{ Decision variable } \\
\hline$T$ & Inventory cycle time \\
\hline \multicolumn{2}{|c|}{} \\
\hline$Q$ & Order quantity of injections (units). \\
\hline$c O_{2}$ & The amount of carbon emissions. \\
\hline$A_{E C}$ & Amount of carbon emissions during set-up and transportation. \\
\hline$h_{E C}$ & Amount of carbon emissions caused by holding injections in the inventory system. \\
\hline$c_{E C}$ & Amount of carbon emissions produced during preparation time. \\
\hline \multicolumn{2}{|c}{ Objective function } \\
\hline$T C(Q)$ & Total cost per unit time (\$ /unit time). \\
\hline & \\
\hline Minimize $T C(Q)$ Problem \\
\hline
\end{tabular}

\subsection{Assumptions}

The proposed model of Remdesivir injection is based on the assumption given below

- Only one type of injection (Remdesivir) is considered.

- The demand rate for the Remdesivir injection is considered to be carbon emissions sensitive which is given by $R=a-k c o_{2}$ where $a>0$ is scale demand, $k$ carbon emissions elasticity and $\mathrm{CO}_{2}$ is the amount of carbon emissions.

- To reduce carbon emissions, carbon tax policy is levied.

- The injection loses its utility due to maintenance at the rate $\theta(0 \leq \theta<1)$.

- Shortages are not allowed. 


\section{Problem Formulation}

Initially the order quantity $Q$ is taken into consideration. Here only one type of injection (Remdesivir) is considered because all the medicines have different demand, life span in shipment temperature and provision level requirement. Storage temperature of Remdesivir injection is below $30^{\circ} \mathrm{C}$ (below $86^{\circ} \mathrm{F}$ ) and account of this tough pandemic, demand of the injection continuously increasing. Hence, the rate of change of inventory level during $[0, T]$ is given by the following differential equation

$$
\frac{d I(t)}{d t}=a-k c o_{2}, 0 \leq t \leq T
$$

Using the boundary condition $I(T)=0$, the inventory level describes by the following equation

$$
I(t)=\frac{\left(a-k \mathrm{co}_{2}\right)}{\theta}\left(\mathrm{e}^{\theta(T-t)}-1\right), 0 \leq t \leq T
$$

Consequently, The order quantity $Q=I(0)=\frac{\left(a-k c o_{2}\right)}{\theta}\left(\mathrm{e}^{\theta T}-1\right)$

Now, calculating cost components related to proposed model are as follows

The ordering cost $O C=\frac{A}{T}$

The Remdesivir injection needs to be proper storage facilities. Thus holding cost is given by

The holding cost is $H C=-\frac{(h+c \theta)\left(k c o_{2}-a\right)\left(e^{\theta T}-1-\theta T\right)}{T \theta^{2}}$

Carbon emissions during set-up activity, holding inventory and spoilage is given by following equation:

$$
C_{2}=\frac{A_{E C}}{T}-\frac{h_{E C}\left(k c o_{2}-a\right)\left(e^{\theta T}-1-\theta T\right)}{T \theta^{2}}+\frac{C_{E C}\left(k c o_{2}-a\right)\left(e^{\theta T}-1\right)}{T}
$$

To reduce amount of carbon emissions, carbon tax policy is essential to impose which is given by

$$
C T C=C_{T}\left(\frac{A_{E C}}{T}-\frac{h_{E C}\left(k c o_{2}-a\right)\left(e^{\theta T}-1-\theta T\right)}{T \theta^{2}}+\frac{C_{E C}\left(k c o_{2}-a\right)\left(e^{\theta T}-1\right)}{T}\right)
$$

From equations (4) to (7), the total cost of inventory is given by 


$$
\begin{aligned}
T C= & \frac{1}{T}\left(A-\frac{(h+c \theta)\left(\frac{k}{T}\left(A_{E C}-\frac{h_{E C}\left(k c o_{2}-a\right)\left(e^{\theta T}-1-\theta T\right)}{\theta^{2}}+C_{E C}\left(k c o_{2}-a\right)\left(e^{\theta T}-1\right)\right)-a\right)\left(e^{\theta T}-1-\theta T\right)}{\theta^{2}}\right. \\
& +c_{T}\left(A_{E C}-\frac{h_{E C}\left(\frac{k}{T}\left(A_{E C}-\frac{h_{E C}\left(k c o_{2}-a\right)\left(e^{\theta T}-1-\theta T\right)}{\theta^{2}}+C_{E C}\left(k c o_{2}-a\right)\left(e^{\theta T}-1\right)-a\right)\left(e^{\theta T}-1-\theta T\right)\right.}{\theta^{2}}\right. \\
& \left.+C_{E C}\left(-\frac{k}{T}\left(A_{E C}-\frac{h_{E C}\left(k c o_{2}-a\right)\left(e^{\theta T}-1-\theta T\right)}{\theta^{2}}+C_{E C}\left(k c o_{2}-a\right)\left(e^{\theta T}-1\right)\right)+a\right)\left(e^{\theta T}-1\right)\right)
\end{aligned}
$$

Equation (8) is a function of cycle time $T$, for optimal value of total $\operatorname{cost} T C$, we need to set $\frac{\partial T c}{\partial T}=0$.

\section{Numerical Validation}

Using global optimization method, proposed model proceeding following steps:

Step-I: Differentiate the cost function (8) partially w.r.t. decision variable $T$.

Step-II: Assign the values to all inventory parameters other than cycle time $T$.

Step-III: $\frac{\partial(T C)}{\partial T}=0$ yields optimum value of cost function.

Step-IV: Solve the equations for all cost functions and decision variable.

The following numerical value of inventory parameters are considered to show the real world application.

$a=500, c=\$ 20$ perinjection, $h=\$ 0.1$ perinjection, $A=\$ 200$ per order, $h_{E C}=0.02$, $A_{E C}=20, \theta=0.1, k=0.3, C_{T}=2, C O_{2}=20, C_{E C}=2$

Based on above numerical values, we get $\frac{\partial^{2}(T C)}{\partial T^{2}}=1611.92>0$ is a sufficient condition for convexity and the optimal solution is

Cycle time $T=0.6695$, total $\operatorname{cost} T C=\$ 885.06$, carbon emissions is $C E=\$ 135.44$ then carbon tax levied is $C T C=\$ 270.88$.

\section{Sensitivity Analysis}

In this section, sensitivity analysis is carried out in order to examine the impact of change due to the inventory parameters on the total cost. It has been made by varying $-20 \%$ to $+20 \%$ for the individual parameters by keeping all other parameters same.

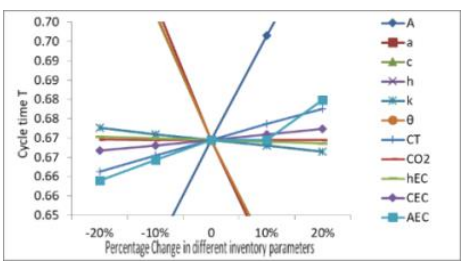

Figure 1(a) Cycle time

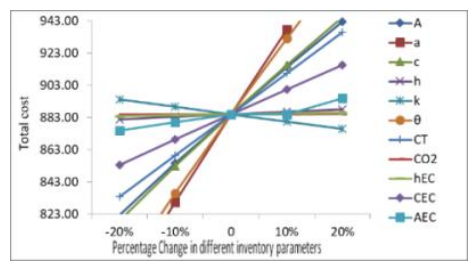

Figure 1(b) Total Cost 


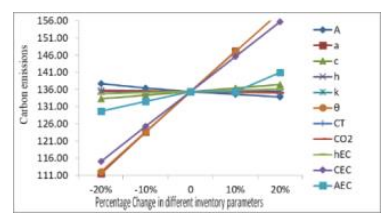

Figure 1(c) Carbon Emissions

Figure 1(a) shows the percentage increase in set up cost, scale demand, purchase cost and deterioration rate are highly sensible to cycle time as they increase with set up cost while it decrease with scale demand, purchase cost and deterioration rate. The rest of the inventory parameters such as holding cost, carbon emissions elasticity, carbon tax, amount of carbon emission and carbon emissions due to set-up, holding and preparation activity have negligible impact on cycle time.

As depicted in Figure. 1(b), it can be shown that due to scale demand, purchase cost, deterioration rate, carbon tax and carbon emission during set-up and purchase activity increases total cost. Total cost is positively affected by set-up cost. Total cost gets increases with holding cost whereas it decreases with rise in carbon emission elasticity. The amount of carbon emissions and activity of holding inventory have managerial impact on total cost.

Figure.1(c) exposed that the inventory parameters scale demand, purchase cost, deterioration rate, and carbon emission during set-up and purchase activity increases carbon emissions. Set-up cost has reversible effect on carbon emissions. Holding cost, carbon emission elasticity, carbon tax and carbon emission during holding the inventory have negligible effect on carbon emissions.

\section{Conclusion}

In this pandemic, the corona virus has been continuously spreading among individuals since December 2019. Around the world, several efforts have been made by researchers and doctors to develop safe and effective medications to prevent corona-infected individuals. And they got succeeded, which can elicit mucosal and cellular immunity. But with the wide use of medicines, there is a big challenge in front of us, carbon emissions. The proposed article exhibited the detailed analysis of carbon emissions, from where it produced. In order to reduce it, the manufacturing process should be modified, transporting vehicles are well designed and storing capacity should also be improved. The spoilage of medicines is not affordable. The proposed model is examined analytically and graphically by minimizing the total cost. A sensitivity analysis is carried out to study the impact of different inventory parameters on total cost and carbon emissions. This model can further be extended by imposing other carbon policies like carbon cap-and-trade, carbon cap and offset by allowing shortages incorporating the preservation technology.

\section{Acknowledgement}

The authors thank DST-FIST file \# MSI-097 for the technical support to the department. Second author (Ekta Patel) would like to extend sincere thanks to the Education Department, Gujarat State for providing scholarship under Scheme of Developing High quality research (Student Ref No: 201901380184). 


\section{References}

1. Benjaafar, S., Li, Y., \& Daskin, M. (2012). Carbon footprint and the management of supply chains: Insights from simple models. IEEE transactions on automation science and engineering, 10(1), 99-116.

2. Bouchery, Y., Ghaffari, A., Jemai, Z., \& Dallery, Y. (2012). Including sustainability criteria into inventory models. European Journal of Operational Research, 222(2), 229-240.

3. Chen, X., Benjaafar, S., \& Elomri, A. (2013). The carbon-constrained EOQ. Operations Research Letters, 41(2), 172-179.

4. Datta, T. K. (2017). Effect of green technology investment on a productioninventory system with carbon tax. Advances in Operations Research, 2017, 1-12.

5. Dye, C. Y., \& Yang, C. T. (2015). Sustainable trade credit and replenishment decisions with credit-linked demand under carbon emission constraints. European Journal of Operational Research, 244(1), 187-200.

6. He, P., Zhang, W., Xu, X., \& Bian, Y. (2015). Production lot-sizing and carbon emissions under cap-and-trade and carbon tax regulations. Journal of Cleaner Production, 103, 241-248.

7. Mishra, U., Wu, J. Z., \& Chiu, A. S. F. (2019). Effects of carbon-emission and setup cost reduction in a sustainable electrical energy supply chain inventory system. Energies, 12(7), 1226.

8. Mishra, U., Wu, J. Z., \& Sarkar, B. (2020). A sustainable production-inventory model for a controllable carbon emissions rate under shortages. Journal of Cleaner Production, 256, 120268.

9. Mishra, U., Wu, J. Z., \& Sarkar, B. (2021). Optimum sustainable inventory management with backorder and deterioration under controllable carbon emissions. Journal of Cleaner Production, 279, 123699.

10. Sarkar, B., Sarkar, M., Ganguly, B., \& Cárdenas-Barrón, L. E. (2021). Combined effects of carbon emission and production quality improvement for fixed lifetime products in a sustainable supply chain management. International Journal of Production Economics, 231, 107867.

11. Yadav, S., \& Khanna, A. (2021). Sustainable Inventory Model for Perishable Products with Expiration Date and Price Reliant Demand under Carbon Tax Policy. Process Integration and Optimization for Sustainability, 5(3), 1-12.

\section{About Our Authors}

Nita H. Shah is the head of Department of Mathematics in Gujarat University, India. She received her $\mathrm{PhD}$ in Statistics from Gujarat University. She was post-doctoral visiting research fellow of University of New Brunswick, Canada. Her research interests include inventory modeling in supply chain, robotic modeling, Mathematical modeling of infectious diseases, image processing, Dynamical Systems and its applications etc. 
Ekta Patel holds a master's degree in mathematics at M.S. University, Baroda in 2010. Since August 2019, she is a research scholar (Ph.D.) at Gujarat University in inventory management. She got her M. Phil. degree in 2019 from Gujarat University.

Kavita Rabari achieved her master's degree in Mathematics (2018). She is pursuing her Ph.D. degree in inventory management, since 2019. She is an assistant Professor at department of mathematics, DKV arts and science college, Jamnagar, Gujarat, India. 